\title{
Assessment of potential drug-drug interactions among outpatients receiving cardiovascular medications at Jimma University specialized hospital, South West Ethiopia
}

\author{
Legese Chelkeba $^{\mathrm{a}, \mathrm{b}} *$, Fessahaye Alemseged ${ }^{\mathrm{c}}$, Worku Bedada $^{\mathrm{a}}$
}

\begin{abstract}
${ }^{\mathrm{a}}$ Department of Pharmacy, College of Public Health and Medical Sciences, Jimma University, Jimma, Ethiopia,

${ }^{\mathrm{b}}$ Research Center for Rational Use of Drugs, Tehran University of Medical Sciences, Tehran, Iran, ${ }^{\mathrm{c}}$ Department of Epidemiology, College of Public Health and Medical Sciences, Jimma University, Jimma, Ethiopia

Received: 8 January 2013 Accepted: 27 January 2013

\section{*Correspondence to: \\ Legese Chelkeba, \\ Email: \\ legese.chelkeba@gmail.com}

(C) 2013 Chelkeba L et al. This is an open-access article distributed under the terms of the Creative Commons Attribution License, which permits unrestricted use, distribution, and reproduction in any medium, provided the original work is properly cited.
\end{abstract}

\begin{abstract}
Background: The quality of pharmacotherapy is highly dependent on the process of choosing a drug in relation to nature of the disease. Several factors should be considered in choosing optimal pharmacotherapeutics strategy including efficacy, safety, availability and cost of the drugs. The objective of this study was to assess potential drug-drug interactions and risk factors in outpatients taking cardiovascular drugs at Jimma University specialized hospital.

Methods: A cross-sectional study was conducted from Feb. to April, 2011on patients visiting the cardiac clinic of Jimma University Specialized hospital. A sample of 332 outpatients who were taking cardiovascular medications at study clinic was studied. MicroMedex software was used to screen drug-drug interactions and SPSS for windows software versions-16.0 was used for data analysis.

Results: A total of 1249 drugs with average of 3.76 drugs per prescription were prescribed for the 332 patients. The frequency of potential DDIs was found to be $241(72.6 \%)$. Among these $200(67.3 \%)$ were of "moderate" severity and 164 $(55.2 \%)$ were delayed in onset. The most common potential DDI observed was between Enalapril and Furosemide (20\%). Patients who prescribed many drugs $(\mathrm{AOR}=4.09 ; \mathrm{P}=0.00)$ by medical intern had a higher risk of developing potential DDIs $(\mathrm{AOR}=4.6 ; \mathrm{P}=0.00)$.

Conclusions: Patients with cardiovascular disorders are subjected to high risk of potential drug-drug interactions and the number of drugs prescribed and educational level of the prescribers has a high significantly associated with the occurrence of potential drug-drug interactions. Therefore, it is imperative that further studies need to be conducted to identify reasons for and tackle the problem and provide appropriate mechanisms for management.
\end{abstract}

Keywords: Drug-drug interactions, Cardiovascular, Outpatients

\section{INTRODUCTION}

The quality of pharmacotherapy is highly dependent on the process of choosing a drug in relation to nature of the disease. In the process of choosing the optimal pharmacotherapeutics strategy, factors like route of administration, dose, contraindications, the potential for adverse drug reactions and cost play an important role. The possibility of a drug influencing the safety or efficacy of another drug (a drug-drug interaction) is an additional variable in making the optimal choice for pharmacotherapy. Adverse consequences of drug interactions have been shown in various studies. In the Harvard Medical Practice study of ADEs, $20 \%$ of events in an acute hospital in-patient setting were drug related, of these, $8 \%$ were considered to be due to DDIs. ${ }^{1}$

During the last decades in Ethiopia, as elsewhere, the population has aged, causing an increase in the level of chronic diseases such as cardiovascular and degenerative diseases and a consequent increment in medication. Polypharmacy is now common, and carries a high risk of drug-drug interactions and drug-disease interactions. These may cause adverse effects, or the therapeutic effects of the combined medicines may change, with serious consequences for health. For example, a prospective observational study from Oct 2007 to Apr 2008 was carried out in 'cardiology department' of a 
hospital in South India found $30.67 \%$ incidence of potential drug-drug interaction. ${ }^{1}$ Furthermore, study done in Mexico City on 624 ambulatory patients over 50 years of age with non-malignant pain syndrome showed that $80.0 \%$ of patients had prescriptions implying one or more potential drug-drug interactions. The study also found that advanced age, polypharmacy and having cardiovascular disorders were among the common factors contributing for increasing drug interactions. ${ }^{2}$

Besides, the health system in Ethiopia is totally dependent on the skills and knowledge of health professionals to identify and correct possible interactions. No software is utilized at any levels and types of health care system in Ethiopia to detect or monitor prescriptions for possible drug-drug interactions. Studies have suggested that medication use can be improved by better communication among patients, physicians, and pharmacists. $^{3}$ This is also nearly absent in Ethiopian health care system. Health system is also loosely controlled, patients are buying drugs as over-the-counter (OTC) and if not identified through history, there is a high possibility for interactions between prescription and OTC drugs. Furthermore, due to economic problems, the probability of monitoring patients with concomitantly existing diseases using sophisticated instruments is not feasible posing the patient to drug-disease interactions. In Ethiopia, inappropriate prescription of drugs with potential interactions causing serious risks to patient health has not been yet studied. The present study sought to determine the frequency of potential drug-drug interactions and associated factors among outpatients receiving cardiovascular medications at Jimma University specialized hospital in cardiac clinic.

\section{METHODS}

The present study was conducted from February 1 to April 2011 at Jimma university specialized hospital which is located in Jimma town, Southwest Ethiopia. Jimma University Specialized Hospital is one of the oldest public hospitals found in the country. Currently, it is the only teaching and referral hospital in the South Western region of the country. It provides specialized health services through its medical and other clinical and diagnostic departments for approximately 9,000 inpatients and 80,000 outpatients each year with bed capacity of 450 . It accommodates a total of more than 550 staffs out of which 395 are health professionals including 36 specialists, 77 residents, 150 medical interns, 30 dental interns, around 10 pharmacists and the rest are nurses and medical laboratory technologists. Cardiovascular clinic is one of the chronic follow up clinics run twice weekly. The service is rendered by internists, medical residents, medical interns, and nurse. There were 2101 patients registered for follow up to December 24, 2010.

Cross-sectional data from 332 outpatients who made visit were collected. The variables analyzed were general characteristics of the patients (age, sex), concomitantly existing diseases, number of drugs prescribed and the educational level of the prescribers (medical interns, residents). Patients included in the study were those who were treated on outpatient basis, whose medication profile contained at least two drugs of which one belongs to drugs for cardiovascular diseases, diagnosed with one or more cardiovascular diseases such as heart failure, hypertension, ischemic heart diseases or arrhythmias, and having three or less months follow. Pediatric age group and pregnant women were treated in separate clinics and were not included in the study.

The data collection period was three months and the follow up service for adult patients with cardiovascular diseases was Friday. So, estimated daily load of patients with cardiovascular diseases was 120 . This made of 120 adult outpatients with cardiovascular diseases visiting the cardiac follow up clinic per week and about 480 per month. To get sampling interval the expected patients with cardiovascular diseases was divided by the sample size (332) which was approximately 4. Therefore, information required from card of every fourth patient coming to the follow up clinic was recorded until the total 332 patients were obtained.

Necessary information such as age, sex, concomitantly existing disease, prescribed drugs and education levels of the prescribers were obtained from patient medical cards and prescription after the patient visited the physicians and additional data were obtained through physician interview if they forgot writing their education levels. MicroMedex electronic database was used to identify and analyze the frequency of potential DDIs.

In this database potential drug-drug interactions are classified based on severity, onset of interaction and documentation status. DDI severity was classified as major, moderate, or minor. Major DDIs may be lifethreatening, and medical intervention may be necessary to minimize or prevent serious adverse effects. Moderate DDIs may result in an exacerbation of the patient's condition and may require an alteration in therapy and minor DDIs have limited clinical effects. The onset of potential DDIs was classified as rapid, delayed, or not specified. Rapid-onset DDIs lead to the clinical "conflict" or adverse effects within 24 hours of drug administration. Delayed-onset DDIs did not lead to the onset of clinical conflict or adverse effects within the first 24 hours following drug administration. The documentation status of the potential DDI was classified as excellent, good, fair, poor, or unlikely. Excellent indicates controlled studies have clearly established the existence of the drug interaction. Good means the documentation strongly suggests that a drug interaction exists, but well-controlled studies are lacking whereas fair refers to us available documentation is poor, but pharmacological considerations may lead clinicians to suspect the existence of a drug interaction; or documentation may be good for a pharmacologically similar drug. 
Quantitative data was analyzed using SPSS for Windows version 16.0. Descriptive analysis was performed to assess absolute and relative frequencies of categorical variables. A bivariate analysis to identify potential factors associated with drug-drug interactions was performed using the chi-square test. Statistically significant associations and plausible variables were included in logistic regression model using the backward stepwise method to control confounding effects. Correlation terms and interactions among selected variables were also explored, and goodness of fit test was assessed for the best model. Variables that were explored in the bivariate analysis were: age, sex, number of drugs prescribed, concomitantly existing diseases and educational levels of the prescribers. All P-values were obtained from twotailed tests and the significance level selected was $\mathrm{P}=$ 0.05 .

\section{RESULTS}

A total of 332 patients who were prescribed 1249 drugs (average 3.76 drugs per prescription) were enrolled in this study. The median age of patients was 58 years (range 2575 years) and $51.5 \%$ were women. Out of all patients, $72.6 \%$ (120 females and 121 males were at risk of encountering 297 drug-drug interactions. Out of the 28 $(8.4 \%)$ patients for which two drugs prescribed, potential DDIs was observed in $11(39.3 \%)$ and of $117(35.2 \%)$ patients prescribed with three drugs $70(59.8 \%)$ were observed to have potential DDIs. Among 85 (25.6\%) patients taking four drugs, 60(70.6\%) had potential DDIs and those for whom five or more drugs prescribed, $97.5 \%$ had DDIs. The most commonly existing co-morbidity with cardiovascular disorders in the current study was peptic ulcer $(61,40.1 \%)$ followed by infectious disease $(35,23 \%)$, specifically community acquired pneumonia for which macrolides or doxycycline were prescribed and urinary tract infections for which norfloxacin was prescribed (Table 1). There was a direct relationship between the professional status of the prescribers and the frequency of potential DDIs ( $\mathrm{AOR}=4.6, \mathrm{p}=0.00$ ).

Table 1: The distribution of DDIs by patients' demographics and clinical characteristics $(\mathbf{n}=332)$ at JUSH, Jimma, May 2011.

\begin{tabular}{|lll|}
\hline Variables & $\begin{array}{l}\text { Patients without DDIs on their } \\
\text { presprescription }\end{array}$ & $\begin{array}{l}\text { Patients with DDIs on their } \\
\text { prescription }\end{array}$ \\
\hline Gender & $40(24.8 \%)$ & $121(75.2 \%)$ \\
\hline Male & $51(29.8 \%)$ & $120(70.2 \%)$ \\
\hline Female & & $12(67.1 \%)$ \\
\hline Age range (years) & $9(42.9 \%)$ & $14(56 \%)$ \\
\hline $15-25$ & $11(44 \%)$ & $54(73 \%)$ \\
\hline $26-36$ & $20(27 \%)$ & $60(68.8 \%)$ \\
\hline $37-47$ & $26(30.2 \%)$ & $67(72.8 \%)$ \\
\hline $48-58$ & $25(27.2 \%)$ & $34(72.3 \%)$ \\
\hline $59-69$ & $13(27.7 \%)$ & $45(73.8 \%)$ \\
\hline$\geq 70$ & & $8(89 \%)$ \\
\hline Diseases & $16(26.2 \%)$ & $33(97 \%)$ \\
\hline Peptic ulcers & $1(11 \%)$ & $29(83 \%)$ \\
\hline Diabetes mellitus & $1(3 \%)$ & $5(83.3 \%)$ \\
\hline Headache and back pain & $6(17 \%)$ & $6(85.7 \%)$ \\
\hline Infectious & $1(16.7 \%)$ & \\
\hline Epilepsy & $1(14.3 \%)$ & $11(39.3 \%)$ \\
\hline Asthma & & $70(60 \%)$ \\
\hline Number of drugs used & $17(60.7 \%)$ & $60(70.6 \%)$ \\
\hline Two & $47(40 \%)$ & $80(97.6 \%)$ \\
\hline Three & $25(29.4 \%)$ & \\
\hline Four & $2(2.4 \%)$ & \\
\hline Five or greater & & \\
\hline
\end{tabular}


Table 2: Patterns of potential DDIs by clinical significance (n= 297) at JUSH, Jimma, May 2011.

\begin{tabular}{|lll|}
\hline Pattern & Frequency & Percent $(\%)$ \\
\hline Severity & \\
\hline Major & 88 & 29.6 \\
\hline Moderate & 200 & 67.3 \\
\hline Minor & 9 & 3.1 \\
\hline Onset & \\
\hline Rapid & 123 & 41.4 \\
\hline Delayed & 164 & 55.2 \\
\hline Not Specified & 10 & 3.4 \\
\hline Documentation & & \\
\hline Excellent & 43 & 14.5 \\
\hline Good & 224 & 75.4 \\
\hline Fair & 30 & 10.1 \\
\hline
\end{tabular}

Table 3: Classification of category of drug associated with a high risk of potential DDIs $(\mathbf{n}=\mathbf{8 7 2})$ at JUSH, Jimma, May 2011.

\begin{tabular}{|llll|}
\hline Rank & Therapeutic category & Frequency & Percent $(\%)$ \\
\hline 1 & Cardiovascular drugs & 676 & 77.5 \\
\hline 2 & NSAIDS*** & 66 & 7.7 \\
\hline 3 & Antimicrobials & 61 & 7 \\
\hline 4 & Antacids & 26 & 3 \\
\hline 5 & Anti diabetics & 24 & 2.8 \\
\hline 6 & Proton pump inhibitors & 12 & 1.4 \\
\hline 7 & Anti epileptics & 2 & 0.03 \\
\hline 8 & glucocorticoids & 2 & 0.03 \\
\hline 9 & H $_{2}$-antagonists* & 2 & 0.0 \\
\hline 10 & $\beta_{2}$-agonists** & 1 & 0.01 \\
\hline & $*$ Cimetidine $* *$ Albuterol $* * *$ Non-steroidal anti-inflammatory drugs \\
\hline
\end{tabular}

Table 4: Drugs with a high probability of causing DDIs at JUSH, Jimma, May 2011.

\begin{tabular}{|llll|}
\hline Rank & Drug & Frequency & Percent $(\%)$ \\
\hline 1 & Enalapril & 200 & 23.5 \\
\hline 2 & Furosemide & 120 & 14.1 \\
\hline 3 & Hydrochlorothiazide & 84 & 9.9 \\
\hline 4 & Spironolactone & 78 & 9.2 \\
\hline 5 & Digoxin & 60 & 7 \\
\hline 6 & Atenolol & 50 & 5.9 \\
\hline 7 & Captopril & 40 & 4.7 \\
\hline 8 & Diclofenac & 26 & 3 \\
\hline 9 & Antacid & 23 & 2.7 \\
\hline 10 & Ibuprofen & 20 & 2.3 \\
\hline 11 & Amlodipine & 16 & 1.9 \\
\hline 19 & Lovastatin & 16 & 1.9 \\
\hline 13 & Indomethacin & 12 & 1.4 \\
\hline 14 & Clarithromycin & 12 & 1.4 \\
\hline 15 & Erythromycin & 12 & 1.4 \\
\hline 12 & Aspirin & 10 & 1.2 \\
\hline 16 & Omeprazole & 10 & 1.2 \\
\hline 17 & Glyburide & 10 & 1.2 \\
\hline 18 & Nifedipine & 8 & 0.94 \\
\hline
\end{tabular}




\begin{tabular}{|llll|}
\hline 20 & Propranolol & 8 & 0.94 \\
\hline 24 & Insulin & 8 & 0.94 \\
\hline 23 & Metformin & 6 & 0.7 \\
\hline 21 & Doxycycline & 5 & 0.6 \\
\hline 22 & Cimetidine & 4 & 0.5 \\
\hline 25 & Prednisolone & 4 & 0.5 \\
\hline 29 & Norfloxacin & 4 & 0.5 \\
\hline 26 & Albuterol & 2 & 0.2 \\
\hline 27 & Phenobarbital & 2 & 0.2 \\
\hline 28 & Phenytoin & 2 & 0.2 \\
\hline
\end{tabular}

Table 5: Distribution of 15 potentially interacting drug pairs with their clinical significance and possible adverse outcomes at JUSH, Jimma, May 2011.

\begin{tabular}{|c|c|c|c|c|}
\hline Rank & Drug Pairs & Frequency & $\begin{array}{l}\text { Clinical } \\
\text { significance }\end{array}$ & Possible adverse out come \\
\hline 1 & Enalapril -Furosemide & 59 & Moderate & Postural hypotension (first dose) \\
\hline 2 & Enalapril-HCT** & 57 & Moderate & Postural hypotension (first dose) \\
\hline 3 & Enalapril-Spironolactone & 39 & Major & Hyperkalemia \\
\hline 4 & Digoxin-Furosemide & 31 & Moderate & Hypokalemia \\
\hline 5 & Digoxin-Spironolactone & 30 & Major & $\begin{array}{l}\text { Digoxin toxicity (nausea, vomiting, } \\
\text { cardiac arrhythmias) }\end{array}$ \\
\hline 6 & Digoxin- Atenolol & 15 & Moderate & $\begin{array}{l}\text { AV block and possible digoxin } \\
\text { toxicity }\end{array}$ \\
\hline 7 & $\begin{array}{l}\text { Digoxin-Macrolides* and } \\
\text { Doxycycline }\end{array}$ & 13 & Major & $\begin{array}{l}\text { Digoxin toxicity( nausea, vomiting } \\
\text { and arrhythmias) }\end{array}$ \\
\hline 8 & $\mathrm{HCT}^{* *} *_{-}$Diclofenac & 13 & Moderate & $\begin{array}{l}\text { Decreased diuretic and } \\
\text { antihypertensive efficacy }\end{array}$ \\
\hline 9 & Lovastatin-Macrolides* & 12 & Major & $\begin{array}{l}\text { Increased risk of myopathy or } \\
\text { rhabdomyolysis }\end{array}$ \\
\hline 10 & Captopril-Spironolactone & 12 & Major & Hyperkalemia \\
\hline 11 & Captopril-Furosemide & 11 & Moderate & Postural hypotension (first dose) \\
\hline 12 & Atenolol-Amlodipine & 9 & Moderate & Hypotension and/or bradycardia \\
\hline 13 & Digoxin-HCT** & 8 & Moderate & hyperkalemia \\
\hline 14 & Atenolol-Diclofenac & 8 & Moderate & Decreased antihypertensive effect \\
\hline 15 & HCT-Ibuprofen & 6 & Moderate & $\begin{array}{l}\text { Decreased diuretic and } \\
\text { antihypertensive efficacy }\end{array}$ \\
\hline
\end{tabular}

From the severity point of view, 88 (29.6\%) of the potential DDIs were major, $200(67.3 \%)$ were moderate and $10(3 \%)$ were considered minor. Similarly, among the potential DDIs, 123(41.4\%) were delayed onset, 164 $(55.2 \%)$ were rapid onset and $10(3.4 \%)$ were not specified. Among the potential DDIs, 43 (14.5\%) were with excellent documentation status, $224(75.4 \%)$ good status and $30(10.1 \%)$ fair status (Table 2). Altogether, 297 potential DDIs were observed and involved 872 drugs (Table 3).
The high risk drugs responsible for DDIs are listed in Table 4. Enalapril was found to be the cardiovascular drug with the highest risk of carrying potential DDI; among the non-cardiovascular drugs, Diclofenac was associated with a high number of potential DDIs. The top 15 drug pairs with the potential for interacting are listed below in Table 5 with their clinical significance and possible outcomes. The most common DDI observed was between Enalapril and Furosemide having moderate severity with the possibility of causing first dose hypotension. 
Table 6: Binary logistic regression analysis for factors associated with DDIs at JUSH, Jimma, May 2011.

\begin{tabular}{|llll|}
\hline Variables & Adjusted Odds ratio & $\mathbf{\pm 9 5 \%}$ CI & P-value \\
\hline Age & 0.96 & $0.308-2.33$ & 0.496 \\
\hline Sex & 1.286 & $0.792-2.088$ & 0.310 \\
\hline Number of drugs prescribed & 4.09 & $3.940-5.391$ & 0.000 \\
\hline Co morbidities & 0.966 & $0.678-5.146$ & 1.000 \\
\hline Professional status & 4.566 & $0.146-4.10$ & 0.000 \\
\hline
\end{tabular}

Table 7: Estimates of the logistic regression for variables those were statistically significant at JUSH, Jimma, May 2011.

\begin{tabular}{|llll|}
\hline $\begin{array}{l}\text { Number of drugs } \\
\text { prescribed }\end{array}$ & Crude OR $\mathbf{( 9 5 . 0 \%}$ CI) & $\begin{array}{l}\text { Educational status } \\
\text { of the prescribers }\end{array}$ & Crude OR (95.0\% CI) \\
\hline Two & $4.02(3.499-32.157)$ & Residents & $0.25(0.166-0.842)$ \\
\hline Three & $3.578(3.95-13.4837)$ & Medical interns & 1 \\
\hline Four & $1.48(3.083-5.857)$ & & \\
\hline$\geq$ Five drugs & 1 & & \\
\hline
\end{tabular}

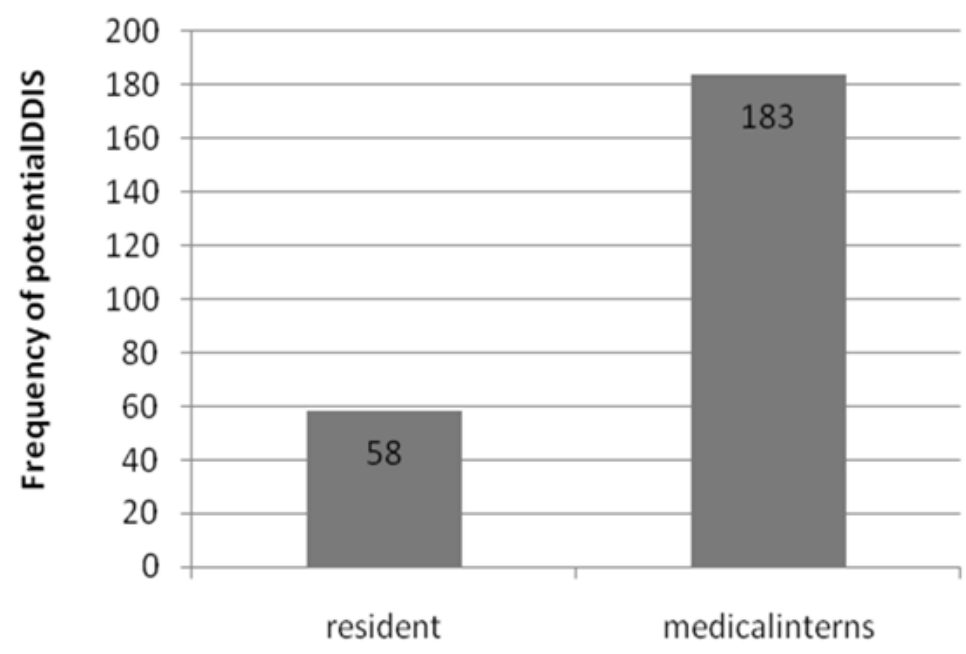

professional status of the prescribers

Figure 1: Relationship between frequency of DDIs and professional status of the prescribers at JUSH, Jimma, May 2011.

\section{DISCUSSION}

Various studies have shown that potential drug-drug and drug disease interactions are frequent when patients receive multiple prescriptions. This is true for both ambulatory and hospitalized patients, and, in many cases, causes adverse effects and changes in therapeutic efficacies of the combined medicines, with consequent poor control of the diseases under treatment. ${ }^{4-6}$

In the present study, we found that the frequency of potential drug-drug interactions was $72.6 \%$ in patients receiving cardiovascular drugs at Jimma University
Specialized Hospital, cardiac clinic; this is higher than the frequency in Thailand $(27.9 \%){ }^{7}$ This difference could be due to the differences in the level of understanding about drug-drug interactions by prescribers in the two studies and the presence of clinical pharmacists reduce the probability of potential drug-drug interactions in study done in Thailand. In other studies the incidence of potential DDIs in elderly patients with arterial hypertension in Croatia and on ambulatory patients over 55 years of age in Mexico city were found to be $90.6 \%$ and $80 \%$ respectively which are far greater than the value obtained in this study. ${ }^{8,9}$ These differences in the incidences of interactions are perhaps a consequence of 
the enrollment of younger patients in this study (average age 55 years) compared to their studies which enrolled elderly patients with mean age of 73 years and 69 years respectively. The other possible explanation for the discrepancy is that the hospital in which this study was conducted uses none of the cardiovascular drugs that are highly interacting such as warfarin, quinine, amiodarone, and verapamil perhaps due to the inaccessibility of these drugs to the hospital or fear of their adverse outcomes in the set up with limited infrastructures to monitor the patients or unfamiliarity of the physicians with these drugs.

The rate of occurrence of potential DDIs in case where residents prescribed the drugs were found to be less likely than when prescribed by the medical interns perhaps due to knowledge gaps between the two levels of training. Gender, sex and concomitantly existing diseases were not identified as predictors of potential DDIs. This is similar to the work done by Vrca and colleagues. ${ }^{9}$

In this study most potential DDIs were moderate (67.3\%). These potential DDIs suggest that there is a need for modification or alteration of therapy such as dosage adjustment. In order to prevent these DDIs, health care providers should have adequate information about DDIs not only via drug information center which can provide evidence-based information to health care professionals but also through encouraging the empowerment of clinical pharmacists that can provide evidence based approach to drugs and thereby prevent drug therapy problems of which DDIs is one. This study also found that $55.2 \%$ of the potential DDIs were of delayed type. For example, the DDI between enalapril and Spironolactone is known to have delayed hyperkalemic effect. This suggests the need for counseling the patients who are at risk for experiencing these DDIs, such as elderly and patients with renal insufficiency. ${ }^{10}$

The documentation status of most of the potential DDIs was good $(75.4 \%)$, suggesting that these potential DDIs may be prevented by evidence-based approach. Perhaps, better approaches are to obtain data on drugs from drug information center or information on drugs from clinical pharmacists during prescribing, thus ideally avoiding DDIs. These results were slightly lower than study done by Souza and Thomas on the epidemiology of drug interactions and Egger and colleagues in terms of severity, onset and documentation status. ${ }^{11,12}$ The reasons for better documentation in the latter studies could be due to better awareness of prescribers about major drug-drug interactions and presence of drug information center and clinical pharmacists.

In this study, cardiovascular drugs posed the maximum risk for potential DDIs followed by NSAIDs which is identical to the study done in Italia and Dutch. ${ }^{13-16}$ Among the various drugs implicated for the potential DDIs, Enalapril ranked first, followed by Furosemide and hydrochlorothiazide. In study done in Italia (Margo et al,
2007), digoxin was the most frequently involved drugs followed by hydrochlorothiazide which was different from this study probably due to the change in the therapy of heart failure. Among the various drugs implicated for the potential DDIs, Enalapril ranked first, followed by Furosemide and hydrochlorothiazide. In study done in Italia $^{16}$, digoxin was the most frequently involved drugs followed by hydrochlorothiazide which was different from this study probably due to the change in the therapy of heart failure.

The non-cardiac drugs frequently involved in potential DDIs in this study were Diclofenac (NSADs), antacids and antimicrobials such as clarithromycin and erythromycin. NSAIDs were commonly prescribed for the treatment of headache and back pain where as antacids were prescribed for dyspepsia.

The three combinations with DDI that were found most frequently in this study were among reported by Vrca and colleagues on the incidence of potential DDIs in elderly patients with arterial hypertension. ${ }^{9}$ In these drug interactions, two of them were moderate severity and without dose adjustment and patient monitoring. Such reactions may result in postural hypotension (EnalaprilFurosemide and Enalapril-HCT). Other frequent potential DDIs was major in severity (Enalapril-Spironolactone) and result in life threatening hyperkalemia and need medical intervention according to DRUG REAX system. Other relatively less frequent major DDIs that were found in this study were Digoxin-Spironolactone, DigoxinClarithromycin/Erythromycin/Doxycycline and Lovastatin-Macrolides. These DDIs potentially result in an increase in digoxin toxicity such as nausea, vomiting and arrhythmia. The mechanisms were supposed to be inhibiting digoxin clearance by Spironolactone and by increasing the bioavailability of digoxin through inhibiting gastrointestinal micro flora that are responsible for degradation of digoxin by Clarithromycin/Erythromycin and Doxycycline. The interaction between lovastatin and macrolides is inhibition of metabolism of Lovastatin by macrolides which result in myopathy and rhabdomyolysis.

The overall number of prescribed drugs $(p=0.000)$ and the level of education of prescribers $(p=0.000)$ were identified as predictors of potential DDISs in this study. Advanced age $(p=0.496)$, sex $(p=0.310)$ and comorbidities $(p=1.000)$ were not found to be the key factors for adverse drug reactions and potential DDIs in this study in contrast to the study done by Sweileh ${ }^{10}$ where these all factors were associated with the frequency of potential drug-drug interaction. These differences might result from the fact that this study involved relatively younger patients in which co morbidities were less likely and therefore, polypharmacy is less compared to their work. The odds of having potential drug-drug interactions in patients taking five or more drugs is 4 times more likely than those patients taking two drugs. Similarly, the odds of having potential drug-drug 
interactions in patients taking five or more drugs 3.6 times more likely than those patients taking three drugs and it is 1.5 times more likely than those patients taking four drugs. This is similar to the study done by Doubova and colleagues. $^{8}$ The odds of having potential drug-drug interactions in cases where medical interns prescribed drugs to the patients is 4 times more likely than when prescribed by residents.

The limitations of the study should not be overlooked. First, the drug-drug interaction found were only potential (it is not clear whether they had resulted in any harm to the patients). No attempt was made in the study to find out if this was the case. Secondly, as a true measure of the occurrence and the risk of receiving drugs with potential interactions, the results in this study were probably slightly underestimated since only prescribed medications were included and most illicit, OTC, and herbal medicines were not included. Third, potential DDIs may be highly dependent on the dose of the individual drugs administered. For example, in this study, aspirin was only prescribed as antiplatelet inhibitor in a daily dose of $100 \mathrm{mg}$. None of these patients were prescribed a higher dose (e.g. $300 \mathrm{mg} /$ day) to inhibit platelet aggregation and non-were prescribed aspirin as analgesic. It is known that some potential DDIs with aspirin are clinically relevant if it is administered in analgesic doses. ${ }^{14}$ DRUG REAX used to evaluate the patient's medication regimen is not able to distinguish between the two different doses scheme. Therefore, potential DDIs involving aspirin that were regarded as clinically irrelevant if dosage of aspirin did not exceed $100 \mathrm{mg} /$ day (e.g. combination of low doseaspirin with ACE inhibitors, which potentially results in a decreased ant-hypertensive effect) were not included in the analysis. Fourthly, only the contribution of medical interns and residents for drug-drug interaction were analyzed and that of internists and nurses are overlooked. This is due to the fact that nurses were not prescribing drugs in specific study place and there were less number of internists in our set up and their role was primarily supervision. Lastly but not least is that identification of potential DDIs was based mainly on the information obtained from the MicroMedex database.

This study was successful in identifying the frequency and pattern of potential DDIs in outpatient cardiovascular chronic care clinic, JUSH. The frequency of potential DDIs was found to be $72.6 \%$ and majority of the DDIs were moderate in severity, delayed in onset and good in documentation status. Enalapril and Furosemide were the high-risk drugs for DDIs. Moreover, medical professionals' level of training is inversely related to the risk of potential DDIs.

Finally, proper emphasis should be given to drug information center and training of clinical pharmacy at Jimma University and across the country, which can play an important role in minimizing DDIs in cardiovascular patients by providing DDI-related information to prescribers. It also we are also recommending to develop a collaborative, patient centered approach in the education of pharmacy professionals to deliver effective drug therapy so the incidence of drug therapy problems will be minimized.

\section{ACKNOWLEDGEMENTS}

The study was supported by Jimma University from the Research Promotion Fund of the University. Addis Ababa University, drug information center for allowing us to use MicroMedex data base to screen drug-drug interactions.

Funding: Research promotion fund of the Jimma

University

Competing interests: No competing interests

Ethical approval: Not required

\section{REFERENCES}

1. Patel VK, Acharya LD, Rajakannan T, Surulivelrajan M, Guddattu V, Padmakumar R. Potential drug interactions in patients admitted to cardiology wards of a south Indian teaching hospital. Australas Med J 2011;4:9-14.

2. Hussar DA. Drug interaction. In: GennaroL, Marderosian A, Hanson $G$ et al. Remington The science and practice of pharmacy. Philadelphia: seventh edition: Lippincott Williams and Willinks 2007; 1746-61.

3. Carter BL, Lund BC, Hayase N, and Chrischilles E. The extent of potential antihypertensive drug interactions in a Medicaid population. Am J Hypertens 2002;15:953-7.

4. Bista D, Palaian S, Shankar P. Understanding the essentials of drug interactions: A potential need for safe and effective use of drugs. Kathmandu Univ Med J 2006:4:421-30.

5. Costa AJ. Potential drug interactions in an ambulatory geriatric population. Fam Pract 1991;8:234-6.

6. Lindblad CI, Artz MB, Pieper CF, Sloane RJ, Hajjar ER, Ruby CM, SchmaderKE, Nalón JT. Potential drug-disease interactions in frail, hospitalized elderly veterans. Ann Pharmacother 2005,39:412-7.

7. Janchawee B, Wongpoowarak W, Owatranporn T, Chongsuvivatwong V. Pharmacoepidemiology study of potential drug interactions in outpatients of a university hospital in Thailand. J Clin Pharm Ther 2005;30:13-20.

8. Doubova (Dubova) SV, Morales HR, Arreola LT, Ortega MS. Potential drug-drug and drug-disease interactions in prescriptions for ambulatory patients over 50 years of age in family medicine clinics in Mexico City. BMC Health Serv Res 2007,7:147.

9. Vrca VB, Marusic S, Erdeljic V, Falamic S, Tomic NG, Rahelic D. The incidence of potential DDIs in elderly patients with arterial hypertension. Pharm World Sci 2010;4:1-7. 
10. Sweileh W. Extent of potential interactions among patients receiving anti-hypertensive medications. Saudi Med J 2005;26:548-52.

11. Egger SS, Ratz Bravo AE, Hess L, Schlienger RG, Krahenbuhl S. Age-related differences in the prevalence of potential drug-drug interactions in ambulatory dyslipidaemic patients treated with statins. Drugs Aging 2007;24:429-40.

12. Souza JM, Thomson JC. Pharmacoepidemiology study of DIs in a Brazil teaching hospital. Clinics 2006;61:515-20.

13. Linnarsson R. Drug interactions in primary health care; a retrospective database study and its implications for the design of a computerized decision support system. Scand J Prim Health Care 1993;11:181-6.
14. Straubhaar B, Krahenbuhl S, Schlienger RG. Prevalence of potential drug interaction in patients with heart failure at hospital discharge. Drug Saf 2006;29:79-90.

15. Buurma H, De Smet PA, Egberts AC. Clinical Risk Management in Dutch Community Pharmacies; the Case of Drug-Drug Interactions. Drug Saf 2006;29:723-32.

16. Magro L, Conforti A, Del Zotti F, Leone R, Iorio ML, Meneghelli I, et al. Identification of severe potential drug-drug interactions using an Italian general-practitioner database. Eur J Clin Pharmacol 2008;64:303-9.

doi:10.5455/2319-2003.ijbcp20130306

Cite this article as: Chelkeba L, Alemseged F, Bedada W. Assessment of potential drug-drug interactions among outpatients receiving cardiovascular medications at Jimma University specialized hospital, South West Ethiopia. Int J Basic Clin Pharmacol 2013;2:144-52. 